\section{$\underset{\substack{\text { hommes } \\ \text { \& migrations }}}{ }$}

\section{Hommes \& migrations}

Revue française de référence sur les dynamiques

migratoires

$1328 \mid 2020$

Les réfugiés dans l'impasse

\title{
Arezki Metref, Rue de la nuit,
}

Koukou éditions, Alger, 2019, 102 pages.

\section{Mustapha Harzoune}

\section{(2) OpenEdition}

\section{Journals}

\section{Édition électronique}

URL : https://journals.openedition.org/hommesmigrations/11000

DOI : 10.4000/hommesmigrations. 11000

ISSN : 2262-3353

\section{Éditeur}

Musée national de l'histoire de l'immigration

\section{Édition imprimée}

Date de publication : 1 janvier 2020

Pagination : 216

ISBN : 978-2-919040-49-0

ISSN : $1142-852 X$

Référence électronique

Mustapha Harzoune, "Arezki Metref, Rue de la nuit, », Hommes \& migrations [En ligne], 1328 | 2020, mis en ligne le 01 janvier 2020, consulté le 04 janvier 2023. URL : http://journals.openedition.org/

hommesmigrations/11000; DOI : https://doi.org/10.4000/hommesmigrations.11000 


\section{Rue de la Nuit}

Arezki Metref, Alger, Koukou éditions, 2019, 102 pages.

«Dans les années obsidionales où le Colonel nous imposait l'enfermement et la trique, beaucoup de jeunes fichaient le camp pour l'Europe» écrit Arezki Metref dans ce roman qui est un

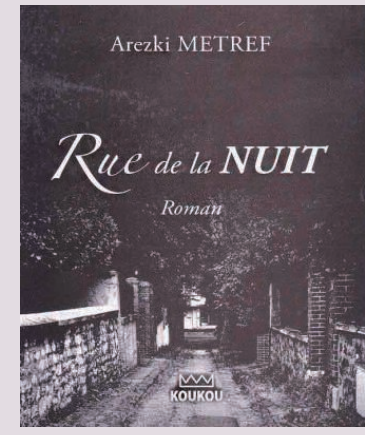

retour vers l'enfance, vers ces eaux troubles des origines où se façonne le destin d'un pays, la "Galérie». Une remontée vers les points de bifurcation des existences d'hommes et de femmes (plutôt absentes ici) qui entraient dans l'adolescence entre 1965 et 1968, années où se déroulent les événements ici rapportés. Deux années pour deux coups d'État. Le premier réussi du «Colonel» contre "Col-Mao», le second, une tentative d'assassinat raté. Deux dates pour dire comment le pouvoir algérien va baisser le rideau sur les espoirs, déjà bien entamés, de l'Indépendance. L'obscurantisme, politique et religieux, va prendre un peu plus ses aises. Exit les velléités de liberté. La nuit tombe sur une rue. Et sur un pays. Vingt-cinq ans plus tard, ces jeunes devenus adultes emprunteront à leur tour le chemin de l'exil pour éviter de se faire zigouiller par un de leurs anciens élèves. "Depuis Bocchus, le beau-père indigne qui livra Jugurtha aux Romains, la malédiction agissait à l'instar d'une divinité réclamant toujours le sacrifice du sang. » Après des années de «pérégrinations forcées à travers le monde», le narrateur s'en revient poser son balluchon à la «Cité des Peupliers», le «brasier natal».

Dans un style dense, trapu, ébouriffé, rythmé par d'efficaces formules poétiques, Arezki Metref plonge le lecteur dans un quartier populaire d'Alger, «la Cité des Peupliers» donc. Comme Naguib Mahfouz ou Albert Cossery, Metref fait du populo son principal personnage, avec sa gouaille, son 
humour, sa truculence, le mordant d'une langue énergique et imagée et son talent pour se réapproprier l'Histoire dont il a trop souvent été le jouet. Les rituelles parties de dominos deviennent alors cet espace sacré pour dire le monde, rester vivants, se jouer des puissants et des injustices. Elles se tiennent au «Café des Amis», du sieur Zongo, amateur iconoclaste, en ces temps de «pureté» et de nationalisme étroit, des Beatles et de «Ticket to ride »... Le bistrot est l'agora où chacun y va de ses commentaires et avis. Au centre d'une respectable galerie de personnages hauts en couleur, tous affublés d'un sobriquet piquant, trône Mucho.

Il a débarqué en juin 1965. Un mystère et autant de bavardages entourent celui que l'on surnomme «Rab el maqla» / « dieu de la tambouille», autrement dit le tout-puissant: voyou ou Robin des bois? Il suscite curiosité, admiration ou crainte chez le commun; tacite détestation du côté de la «Maison du Drapeau» ou du «Minaret». Qu'importe, durant trois ans, «Mucho structurait le temps du Peuplier avec plus de précision et de couleur que les cinq prières quotidiennes de cheikh Zoudj». Mais pourquoi, se demande la vox populi, "jouissait[-il] d'une impunité qui frisait le laxisme»? Legs d'« une guerre qui avait définitivement prouvé que seule la violence comptait»-du moins en ces temps lointains? Mystère! Jusqu'à y compris sa disparition, un soir d'avril 1968 donc...

Pourtant, l'homme et la période furent vite effacés des mémoires. Un peu à la façon stalinienne consistant à gommer des photos et de l'histoire officielles ceux tombés en disgrâce. "On aurait pu penser que la Maison du Drapeau avait trouvé un moyen d'agir sur notre mémoire à notre insu. » C'est donc un enfant de la cité, de retour de moult exils qui tient la chronique. Il se refuse à lire les carnets de «Poteau électrique», la «bibliothèque» du quartier.

Pourquoi? Parce que la mythologie est peut-être préférable à l'Histoire. Pour montrer que l'écriture, notamment dans un pays despotique, est un acte de liberté et de sédition.

M. H. 